\title{
Specifics of automatic switches commutation testing
}

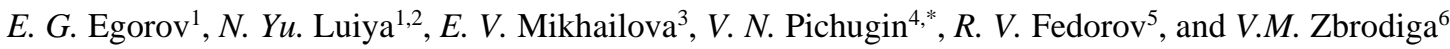 \\ ${ }^{1}$ Chuvash State University named after I.N. Ulyanov, Cheboksary, Russia \\ 2 Joint Stock Company "Cheboksary Electrical Apparatus Plant”, Cheboksary, Russia \\ ${ }^{3}$ Kazan State Power Engineering University, Kazan, Russia \\ ${ }^{4}$ Alatyr branch of Chuvash State University named after I.N. Ulyanov, Alatyr, Russia \\ ${ }^{5}$ Joint Stock Company "Plant "Electropribor"”, Alatyr, Russia \\ ${ }^{6}$ Belarusian State Agrarian Technical University, Minsk, Belarus
}

\begin{abstract}
We demonstrate that the most efficient way to extinguish the short-circuit arc is extinguishing inside the camera with an arc extinguishing grid, which splits it into several smaller arcs. The active resistivity of these partial arcs decreases the amplitude of the current of the short-circuit arc, decreases the angle $\varphi$ between current and voltage, which decreases the amplitude of the return current and enhances the condition for the arc extinguishing. We analyze the process of arc extinguishing in the three-phase circuit. We would like to note that during the extinguishing of the arc in the first extinguishing pole resistance of electric arcs in two other poles deforms the voltage triangle decreasing the coefficients of the scheme from 1.5 to 1.3 according to the experimental data. This allows to decrease the difficulty of the tests for maximum commutation capability. Simultaneously, we consider the necessity of the selection and regulation of the wave parameters (amplitude coefficient and normal mode) of the test circuit according to the standard for test preparation. Taking into account the decrease of the coefficient of the scheme and the real wave parameters will allow to objectively estimate commutation capability and to optimize the parameters pf the contact arc extinguishing system of an automated switch.
\end{abstract}

\section{Introduction}

Modern market of electrical equipment provides a broad specter of protective apparatus manufactured both locally and abroad.

Due to a high demand in modern automatic switches in different areas of industry and military, developing the production of automatic switches was included in the "Development of the industry and competitiveness" program that is directed at the import substitution of the goods produced by foreign companies.

Low-voltage automatic switches are intended for protection of electrical equipment and networks from abnormal (including hazardous) modes of operation, for example, they can facilitate switching off loads during short-circuits, lengthy overvoltage, drops and breaks of the circuit current, etc.; additionally, they can be used for infrequent commutation of nominal currents $[1,2]$.

\section{Methods}

We intend to pay special attention to the arcextinguishing scheme of an automatic switch, because this system has to ensure reliable commutation of nominal currents and breaking short-circuit currents, amplitude of which can exceed $100 \mathrm{kA}$ [1].

Scheme of automatic switch commutation testing can be seen in the Figure 1.
In order to extinguish the short-circuit arc, arcextinguishing cameras with arc-extinguishing grids made of steel plates are used.

The condition for extinguishing an $\mathrm{AC}$ arc after the arc transitions through zero is $U_{B}(t)>U_{B H}(t)$.

One of the key elements of the arc-extinguishing system is plates of the arc-extinguishing grid: their number, thickness and distance between. The arc-extinguishing grid determines the physical dimensions of the arcextinguishing device and the switch off capability of the automatic switch.

\section{Results}

We know that the return current is determined by $[3,4]$ :

$$
U_{0}=\sqrt{\frac{2}{3}} K_{c x} U_{\text {ном }} \sin \varphi
$$

where $U_{\text {nom }}$ is nominal (linear) grid voltage, $\mathrm{V} ; \varphi$ is the phase angle between the voltage and the current in the circuit.

The scheme coefficient $\mathrm{K}_{\mathrm{cx}}$ depends on the scheme of connection of the apparatus to the network it commutates with. When breaking the three-phase chain with a threepole apparatus $\mathrm{K}_{\mathrm{cx}}=1,5$, and when breaking the threephase chain with a three-point apparatus when the

\footnotetext{
* Corresponding author: pvn.chuvsu@yandex.ru
} 


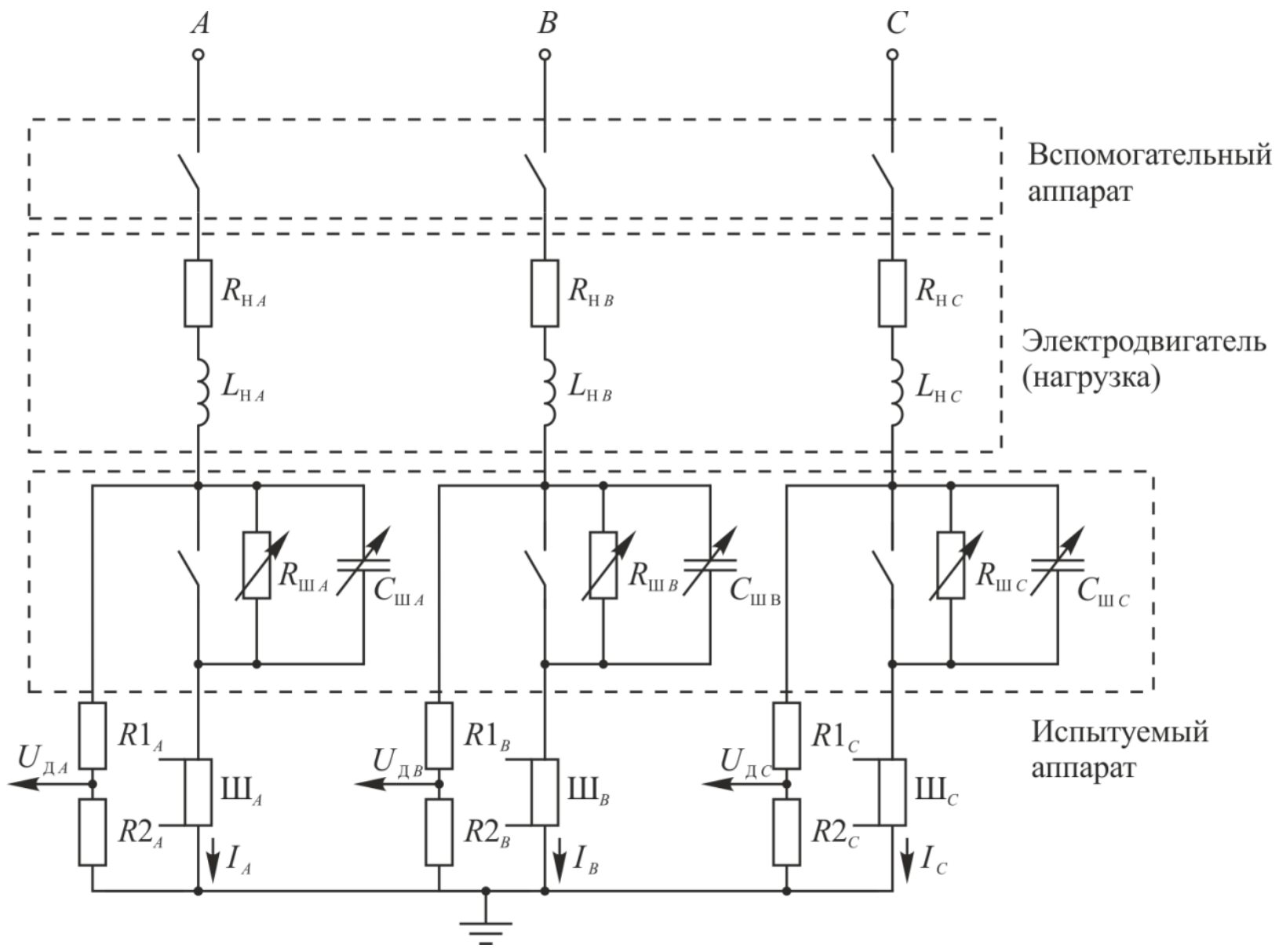

Fig. 1. The scheme of commutation testing a three-phase apparatus.

neutral point of the source and the zero point of the load are grounded $\mathrm{K}_{\mathrm{cx}}=1,0[3,4]$.

Automatic switches have to be able to function when the voltage is 1.1 of $U_{\text {nom }}$ [3], thus the maximum amount value of the recovering voltage is

$$
U_{0 \max }=1,1 \kappa_{0} \kappa_{\mathrm{cx}} \kappa_{\mathrm{a}} \cdot \sqrt{2} \frac{U_{\pi}}{\sqrt{3}} \sin \varphi
$$

where $\kappa_{0}$ is a coefficient that takes into account the resistance of an arc when it is being extinguished.

The influence of the arc's resistivity at the extinguishing pole affects the decrease of the amplitude value of the arc current $U_{\text {в.н.м }}$ because of the decrease in the shift angle. This influence increases with growth of the arc's resistance and can become significant [4].

He high voltage amplitude in the first extinguishing pole will be less if arc extinguishing in two other poles will be efficient, which means a significant voltage drop in these arc gaps (see Figure $2 U_{\text {дА }}$ and $U_{\text {дС }}$ when $i_{\mathrm{B}=0}$ in the first extinguishing pole). This leads to significant distortion of the voltage triangle relative to the case when we assume that the voltage at the contacts while the arc is active does not equal zero, which decreases the scheme coefficient $\kappa_{\mathrm{cx}}$. The value $\kappa_{\mathrm{cx}}$ can be determined using the vector diagram on the Figure 2. When $U_{д \mathrm{~B}}=U_{д \mathrm{C}}=0$, for the phase A.

$$
\kappa_{\mathrm{cx}}=\frac{\bar{U}_{\mathrm{A} 0^{\prime}}}{\bar{U}_{\mathrm{A} 0}}=1,5
$$

where $\bar{U}_{\mathrm{A} 0}=\bar{U}_{\mathrm{A}}$ is phase voltage; $\bar{U}_{\mathrm{A} 0}$ is phase voltage when neutral is displaced to the point 0 .

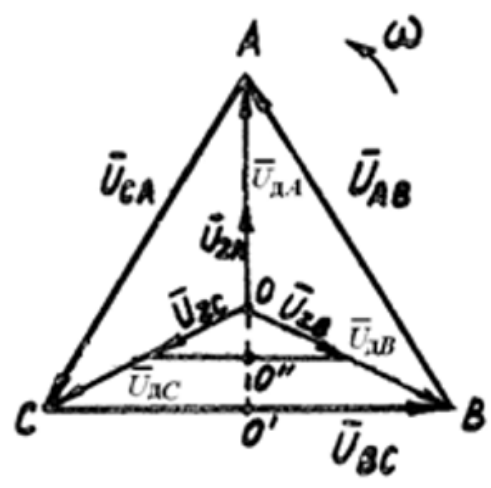

Fig. 2. Three-phase circuit vector diagram. 
When $U_{\text {дВ }}=U_{\text {дС }}=U_{\text {д }} \neq 0$, if $i_{\mathrm{A}}=0$ the scheme coefficient will be determined by: .

$$
\begin{aligned}
& \kappa_{\mathrm{cx}}=\frac{\bar{U}_{\mathrm{A} 0}}{\bar{U}_{\mathrm{A} 0^{\prime \prime}}}=\frac{U_{\phi}+\left(U_{\phi}-U_{\text {д }}\right) \sin 30^{\circ}}{U_{\phi}}= \\
& =1,5-0,5 \frac{U_{\text {д }}}{U_{\phi}}
\end{aligned}
$$

where $\bar{U}_{\mathrm{A} 0 \text { " }}$ is voltage at the contacts in the phase $\mathrm{A}$ taking into account the arc voltage on the poles $\mathrm{B}$ and $\mathrm{C}$.

Based on the experimental research, we have determined that $K_{\mathrm{cx}} \approx 1.1-1.25$ (during commutation tests it is advisable to assume that $K_{\mathrm{cx}}$ equals 1.25).

For the tests of maximum breaking capacity the values of maximum wave parameters can be calculated using the formulas $(3,4,5)$

$$
\left\{\begin{array}{l}
f_{0}=2600 I_{0}^{0,2} U_{0}^{-0,8} \pm 10 \% ; \\
k_{\mathrm{a}}=1,15+0,5 \exp \left(-0,016 f_{0}\right) \pm 0,05,
\end{array},\right.
$$

where $k_{\mathrm{a}}$ is the amplitude coefficient; $I_{0}$ is load current, A; $U_{0}$ is nominal voltage of the load circuit, $\mathrm{B} ; f_{0}$ is the oscillation frequency of the current in the load circuit, $\mathrm{kHz}$.

According to the requirements of the State Standard GOST P50030.2 [6], the following commutation types are recognized $[6,7]$ :

- testing of the nominal breaking capacity;

- testing of the nominal maximum limit of the breaking capacity;

- testing the maximum switching ability;

- testing for short-circuiting separate poles, etc.

Exact technical requirements are set in technical documentation, for instance, for standard production of automatic switches of the first dimension for the maximum switching ability with 160 A nominal current, nominal maximum breaking capacity has to be $I_{\mathrm{cs}}=25 \mathrm{kA}$ (for $380 \mathrm{~V}$ ), $I_{\mathrm{cs}}=20 \mathrm{kA}$ (for $660 \mathrm{~V}$ ).

\section{Discussion}

Taking into account real wave parameters of commutated loads and a decrease in return current by $20 \%$ allows to obtain objective results of commutation tests that confirm the functioning of an automatic switch and to optimize the parameters of its arc-extinguishing device.

In the methods pf the commutation tests listed above in order to objectively evaluate the results of automatic switches testing we need to take into account the real values of the wave parameters of the test circuit according to (5). Furthermore, we need to take into account the deformation of the voltage triangle during arc extinguishing in the first extinguishing pole taking into account arc processes in both other poles of the automatic switch.
The search for and regulation of the values of wave parameters $f_{0}$ and $k_{\mathrm{a}}$ is done according to the requirements of $[4,8]$ using of shunted connections $R_{\text {sh }}$ and capacitors $\mathrm{C}_{\mathrm{sh}}$.

Taking into account the deformation of the current triangle in the three-phase circuit allows decreasing the maximum value of the recovery voltage by $20 \%$.

The results of the commutation tests of the automatic switches allow to assess their functioning and to optimize parameters of the arc-extinguishing device

\section{Conclusions}

1. Short circuit currents during arc extinguishing by automatic switches can achieve several hundred kA, which calls for strict requirements to the construction of the arc-extinguishing device.

2. We recommend taking into account the drop in return current (up to $20 \%$ ) and real wave parameters of the test circuit when designing commutation test methods.

3. In order to ensure operability of automatic switches we recommend developing and introducing synthetic tests into their production.

\section{References}

[1] E.G. Akimov et al., Electrical and electronic devices: Textbook for universities Vol.1: Electromechanical devices, 344 (2010)

[2] A.V. Kabyshev, Low-voltage circuit breakers: study guide, 346 (2011)

[3] I.S. Taev, Electrical contacts and arcing devices of low voltage apparatus, 424 (1973)

[4] E.G. Egorov, Testing and research of low-voltage switching electrical apparatus: a textbook for universities in the specialty "Electrical and electronic apparatus", 448 (2000)

[5] P.A. Kurbatova, Fundamentals of the theory of electrical apparatuses: A textbook for universities, 592 (2015)

[6] GOST 50030.2 - 2010 (IEC 60947-2: 2006). Low-voltage distribution and control equipment. Part 2. Circuit breakers (2010)

[7] V.P. Meshherjakov, Electric arc high power switches. Part II, 429 (2008)

[8] E.G. Egorov, S.P. Ivanova, N.Ju. Luija, A.V. Afanas'ev, A.A. Petrov, Investigation of the breaking capacity of circuit breakers in short circuit mode, Electrical Engineering, 8, 12-15 (2018) 